\title{
Effects of a Leukotriene Antagonist on the Early Hemodynamic Manifestations of Group B Streptococcal Sepsis in Piglets ${ }^{1}$
}

\author{
RONALD N. GOLDBERG, CLEIDE SUGUIHARA, MURRAY M. STREITFELD, \\ ALDO BANCALARI, MARTIN R. CLARK, AND EDUARDO BANCALARI \\ Department of Pediatrics (Division of Neonatology) [R.N.G., C.S., A.B., E.B.] and Departments of Microbiology \\ [M.M.S.] and Obstetrics and Gynecology [M.R.C.], University of Miami School of Medicine, \\ Miami, Florida 33101
}

\begin{abstract}
In order to evaluate the influence of leukotrienes on group B streptococcal (GBS) sepsis we studied the effect of a leukotriene antagonist, FPL 57231, on the early hemodynamic changes occurring secondary to an infusion of live GBS. Paralyzed, mechanically ventilated piglets received a continuous intravenous infusion of bacteria $\left(5 \times 10^{8} \mathrm{org} / \mathrm{kg} / \mathrm{min}\right)$ while systemic arterial pressure and pulmonary artery pressure were measured continuously. Cardiac output was measured by thermodilution; and plasma samples for determination of thromboxane $\mathbf{B}_{2}$ and 6-keto-PGF ${ }_{1 \alpha}$ were taken at preset intervals. In addition to GBS, treatment animals received a continuous infusion of FPL 57231 starting $15 \mathrm{~min}$ after the bacterial infusion was begun. Study animals as a whole responded to bacteria within 15 min with a marked elevation in pulmonary artery pressure from $13.6 \pm 4$ to $44.6 \pm 6 \mathrm{~mm} \mathrm{Hg}(p<0.001)$, and a decline in $\mathrm{PaO}_{2}(79 \pm 9$ to $44 \pm 5 \mathrm{~mm} \mathrm{Hg})(p<$ $0.001)$ and a cardiac output $(0.27 \pm 0.07$ to $0.15 \pm 0.06$ liter $/ \mathrm{min} / \mathrm{kg})(p<0.0001)$. In animals treated with FPL 57231 these changes were reversed or significantly attenuated by $60 \mathrm{~min}$. In the control group $\mathrm{pH}$ deteriorated significantly to $7.17 \pm 0.1$ compared to baseline values ( $p$ $<0.01$ ) by $60 \mathrm{~min}$, while treatment group animals maintained a pH of $7.3 \pm 0.23$. Thromboxane $B_{2}$ and 6-keto PGF $_{1 \alpha}$ were similar in both groups and did not change during the study period. In addition, survival was significantly longer in treatment $(191 \pm 44 \mathrm{~min})$ compared to control animals $(100 \pm 32 \mathrm{~min})(p<0.01)$. These data suggest that FPL 57231 may attenuate the early cardiovascular changes accompanying GBS infection and positively influence survival without modifying thromboxane or 6-keto $\mathrm{PGF}_{1 \alpha}$ levels. These results imply that leukotrienes influence the early hemodynamic manifestations of GBS sepsis. (Pediatr Res 20: 1004-1008, 1986)
\end{abstract}

\section{Abbreviations}

CO, cardiac output

GBS, group B streptococci

Ppa, pulmonary artery pressure

Ppaw, pulmonary wedge pressure

Pra, right atrial pressure

Received January 2, 1986; accepted May 29, 1986.

Correspondence Ronald N. Goldberg. M.D. Department of Pediatrics (R-131) University of Miami School of Medicine, P.O. Box 016960, Miami, FL 33101.

Supported in part by the National Institutes of Health, Grants IR01 HD14940 and 5R01 HL25023, The State of Florida, Department of Health \& Rehabilitative Services, Children's Medical Service and University of Miami/Project: New Born.

' Presented in part at the Society for Pediatric Research, Washington, D.C., May 8,1985 .
Psa, systemic arterial pressure

PVR, pulmonary vascular resistance

SVR, systemic vascular resistance

$\mathbf{T x B}_{2}$, thromboxane $\mathbf{B}_{2}$

5-HETE, 5-hydroxy-6,8,11,14 eicosatetraenoic acid

6-keto $\mathrm{PGF}_{1 \alpha}$, 6-keto prostaglandin $\mathrm{F}_{1 \alpha}$

Investigators have documented beneficial effects of nonsteroidal antiinflammatory agents on hemodynamics $(1,2)$ and survival $(2,3)$ in animal models using group B streptococcal toxin (1) and live organisms $(2,3)$. It has been shown that products of the cyclooxygenase pathway are responsible for many of the cardiovascular alterations seen in the first $2 \mathrm{~h}$ after either toxin (1) of live bacteria (2) are infused. Treatment with indomethacin during this period has resulted in improvement not only in the deleterious hemodynamic effects of GBS $(1,2)$ (i.e. increased $\mathrm{P}$ pa and PVR, and decreased $\mathrm{CO}$ ), but has also resulted in improved survival $(2,3)$. In addition, measurements of $\mathrm{TxB}_{2}$, the stable metabolite of thromboxane $\mathrm{A}_{2}$, and 6-keto PGF $\mathrm{P}_{1 \alpha}$, the stable metabolite of prostacyclin, have shown that improvement in cardiovascular function is associated with a return of these products of arachidonic acid metabolism to baseline levels $(1,2)$.

After these initial hemodynamic and biochemical changes there is an increase in pulmonary capillary permeability, and alterations in Ppa and PVR which have been attributed to the lipoxygenase products of arachidonic acid metabolism $(1,4)$. However, when considering the many actions and interactions of prostaglandins, thromboxane, and leukotrienes (5), some in mimicry and some in opposition to each other, it is not unreasonable to expect important interactions between these substances, especially when they are derived from a common substrate and share elements of the same biochemical pathway. It is possible that many of the early hemodynamic changes attributed to thromboxane $A_{2}$ may in part be related to increased levels of leukotriene $\mathrm{C}_{4}$ and $\mathrm{D}_{4}$.

The purpose of this study was to investigate the role of leukotrienes in the early cardiovascular manifestations of GBS sepsis in a highly lethal animal model using piglets by evaluating the effect of the leukotriene receptor antagonist, FPL 57231, on hemodynamics. Plasma levels of $\mathrm{TxB}_{2}$ and 6-keto $\mathrm{PGF}_{1 \alpha}$ were also examined to detect possible nonspecific effects of this antagonist.

\section{MATERIALS AND METHODS}

Animal model. Ten Yorkshire piglets were anesthetized with pentobarbital $(30 \mathrm{mg} / \mathrm{kg}$, intraperitoneally). A femoral artery 
and vein were cannulated and used for Psa measurement and blood sampling. The left external jugular vein was cannulated and the catheter advanced into the right atrium for measurement of pressure (Pra) and injection of ice cold saline which was used for measurement of $\mathrm{CO}$. A 5F Swan-Ganz thermodilution catheter was introduced into the right external jugular vein and advanced under fluoroscopy into the left pulmonary artery. CO was measured by thermodilution using a cardiac output computer (95510-A, Edwards Laboratory, Santa Ana, CA). The Swan-Ganz catheter was also used to measure Ppa and Ppaw. Heparinized normal saline $(10 \mathrm{U} / \mathrm{ml})$ was infused continuously through the pulmonary artery catheter. Vascular pressures were measured with pressure transducers (model P23 ID; GouldStatham Instruments, Hato Rey, PR) and recorded on a multichannel recorder (model 5 polygraph, S2-925T25, Grass Instrument, Quincy, MA).

A tracheostomy was performed and a $3.5-\mathrm{mm}$ endotracheal tube placed. The animals were ventilated with a time-cycled, pressure-limited, infant ventilator (Sechrist, Model IV-100 B Infant Ventilator, Sechrist Industries, Anaheim, CA). Peak inflation pressure was set at $12 \mathrm{~cm} \mathrm{H}_{2} \mathrm{O}$; PEEP at $2 \mathrm{~cm} \mathrm{H} \mathrm{H}_{2} \mathrm{O}$, and the respiratory rate at 40 breaths $/ \mathrm{min}$. Animals were ventilated with room air. Ventilatory parameters were not altered during the study period. Arterial blood gases were measured prior to, 15, 30 , and $60 \mathrm{~min}$ after bacterial infusion was started $\mathrm{pH} / \mathrm{Blood}$ Gas Analyzer 113, Instrumentation Laboratories, Lexington, MA). Rectal temperature was continuously monitored with a thermistor probe (Yellow Springs Instrument CO., Yellow Springs $\mathrm{OH}$ ), and maintained at $38.0^{\circ} \mathrm{C}$ by means of a servocontrolled radiant warmer.

Animals were paralyzed with pancuronium bromide using an initial dose of $0.2 \mathrm{mg} / \mathrm{kg}$ intravenously followed by an infusion of $0.4 \mathrm{mg} / \mathrm{kg} / \mathrm{h}$. After a 60 -min stabilization period, baseline cardiovascular measurements (Psa, Ppa, CO, Ppaw, and Pra) and arterial blood gases were obtained prior to bacterial infusion. This value will be hereafter referred to as baseline.

Bacterial preparation. Group $\mathrm{B}_{\beta}$-hemolytic streptococci (type Ic) were isolated from the blood of an infant who developed early onset sepsis at the University of Miami/Jackson Memorial Hospital Neonatal Intensive Care Unit. Bacteria for each animal experiment were incubated $18 \mathrm{~h}$ in Todd-Hewitt broth at $37^{\circ} \mathrm{C}$. The broth culture was centrifuged at $1700 \mathrm{rpm}$ for $30 \mathrm{~min}$ and the bacterial pellet was resuspended in sterile Ringer's lactate solution with $5 \%$ dextrose to a concentration determined by serial viable counts to be $1.46 \times 10^{9}$ colony forming units per $\mathrm{ml}$.

Induction of sepsis. Bacterial infusion was begun immediately after baseline values were obtained. Bacteria were infused through a femoral vein at a rate calculated to deliver approximately $5 \times 10^{8}$ organisms $/ \mathrm{kg} / \mathrm{min}$. This infusion was continued until the animal died or $4 \mathrm{~h}$ had elapsed.

The piglets were then randomly assigned to a treatment group composed of five animals (mean $\pm \mathrm{SD}$; weight, $2849 \pm 622 \mathrm{~g}$; age, $11 \pm 2$ days) who received the leukotriene antagonist, FPL $57231(1 \mathrm{mg} / \mathrm{kg} / \mathrm{min}$ for $30 \mathrm{~min}$, followed by a dose of $0.5 \mathrm{mg} /$ $\mathrm{kg} / \mathrm{min} \times 30 \mathrm{~min}$ ) (Fisons plc., Loughborough, U.K.) via a femoral vein beginning after the 15 -min values were obtained. The drug was entirely dissolved in $10 \mathrm{ml}$ of sterile water. Five piglets (weight, $3331 \pm 780 \mathrm{~g}$; age, $11 \pm 4$ days) were assigned to the control group and received $10 \mathrm{ml}$ of normal saline over the same time period.

Aortic and $\bar{P}$ pa were measured continuously throughout the baseline and study periods. CO, Ppaw, and Pra were measured prior to and during the bacterial infusion and at $15,30,45$, and $60 \mathrm{~min}$ after infusion of GBS was begun. Pulmonary vascular resistance was calculated using the formula:

$$
\frac{\overline{\mathrm{P}} \mathrm{pa}-\overline{\mathrm{P}} \mathrm{paw}}{\mathrm{CO} / \mathrm{kg}}
$$

and systemic vascular resistance calculated using the formula:

$$
\frac{\overline{\text { Psa }}-\overline{\text { Pra }}}{\mathrm{CO} / \mathrm{kg} \text {. }}
$$

Blood samples $(1 \mathrm{ml})$ from control and treatment animals were collected for radioimmunoassay of $\mathrm{TxB}_{2}$ and 6-keto $\mathrm{PGF}_{1 \alpha}$ in tubes containing aspirin and EDTA $(0.41$ and $1.95 \mathrm{mg} / \mathrm{ml}$ for 1 $\mathrm{ml}$ blood, respectively). Plasma from these samples was extracted with ethanol, centrifuged to remove precipitated protein, and dried under nitrogen before being reconstituted in $0.5-1.0 \mathrm{ml}$ of phosphate-buffered saline containing $0.1 \%$ gelatin. The method used for their determination has been described previously (2).

Data analyses. Data are expressed as mean \pm SEM. Statistical analyses included repeated measure analysis of variance (6), and the paired and unpaired $t$ tests. Weight and age were compared by a two sample $t$ test, while change from baseline to the point 15 min after the infusion of GBS was started was compared with a paired $t$ test. In addition, the paired $t$ test was used to compare the baseline with 60 min values. Both prebacteria and 15-min postinitiation of GBS baseline values were compared between groups, using an unpaired $t$ test, and found not to be statistically different. These baseline values were combined to present an overall picture of the response to GBS in the piglet. Repeated measure analysis of variance was used to compare the pattern of response to treatment over time from a point $15 \mathrm{~min}$ after GBS started to the subsequent points for the two groups for all variables ( $\overline{\mathrm{P}} \mathrm{pa}, \mathrm{PVR}, \mathrm{SVR}, \overline{\mathrm{P}} \mathrm{sa}, \overline{\mathrm{P}} \mathrm{ra}, \overline{\mathrm{P}}$ paw, heart rate, $\mathrm{CO}, \mathrm{pH}$, $\mathrm{PaCO}_{2}$, and $\mathrm{PaO}_{2}$ ).

\section{RESULTS}

Hemodynamic measurements at baseline and $15 \mathrm{~min}$ after the start of GBS infusion were comparable in control and FPL 57231-treated animals. $\bar{P}$ pa increased significantly in both groups (Fig. 1) and was markedly elevated compared to baseline at 15 $\min (p<0.01)$. Arterial oxygen tension (Fig. 1) was significantly lower than baseline at $15 \mathrm{~min}(p<0.001)$.

After $15 \mathrm{~min}$ of bacterial infusion, $\overline{\mathrm{P}}$ pa in control animals remained fairly stable (Fig. 1). Animals treated with FPL 57231, displayed a gradual reduction in $\overline{\mathrm{P}}$ pa to values which are significantly lower than control animals from 30 to $60 \mathrm{~min}(p<0.01)$, but which were still higher than pre-GBS infusion baseline $(p<$ 0.02).

Arterial oxygen tension in the control animals remained low throughout the study period. In contrast, $\mathrm{PaO}_{2}$ in the FPL 57231 group increased toward baseline values over the study period and was significantly different in the two groups from 30 to $60 \mathrm{~min}$ $(p<0.05)$. However, it remained lower than baseline $(p<0.02)$.

After the initial marked reduction at $15 \mathrm{~min}(p<0.01) \mathrm{CO}$ continued to decline in control animals throughout the experiment (Fig. 2). CO in the FPL 57231-treated animals increased and was significantly greater than that of control animals during the period from 30 to $60 \mathrm{~min}$. In addition, the 60 -min value in this group was not statistically different from baseline.

PVR and SVR increased significantly $(p<0.001)$ with GBS infusion (Fig. 3). Values in the control group remained elevated during the study period while there were significant decreases in PVR $(p<0.01)$ and SVR $(p<0.05)$ in FPL 57231-treated animals. There were no statistical difference in SVR or PVR between baseline and 60-min values.

The $\mathrm{pH}$ in both groups decreased $(p<0.001)$ by $15 \mathrm{~min}$, but thereafter diverged. At the end of the study period animals in the treatment group had a mean $\mathrm{pH}$ of $7.30 \pm 0.23$ while the control group had a pH of $7.17 \pm 0.10(p<0.01)$. The same pattern was found when base excess was compared $(p<0.01)$. There were no statistically significant differences between groups in $\mathrm{PaCO}_{2}$.

Ppaw was compared between groups. This pressure rose significantly for the groups as a whole from $3.8 \pm 3.8$ to $9.6 \pm 1.7$ 


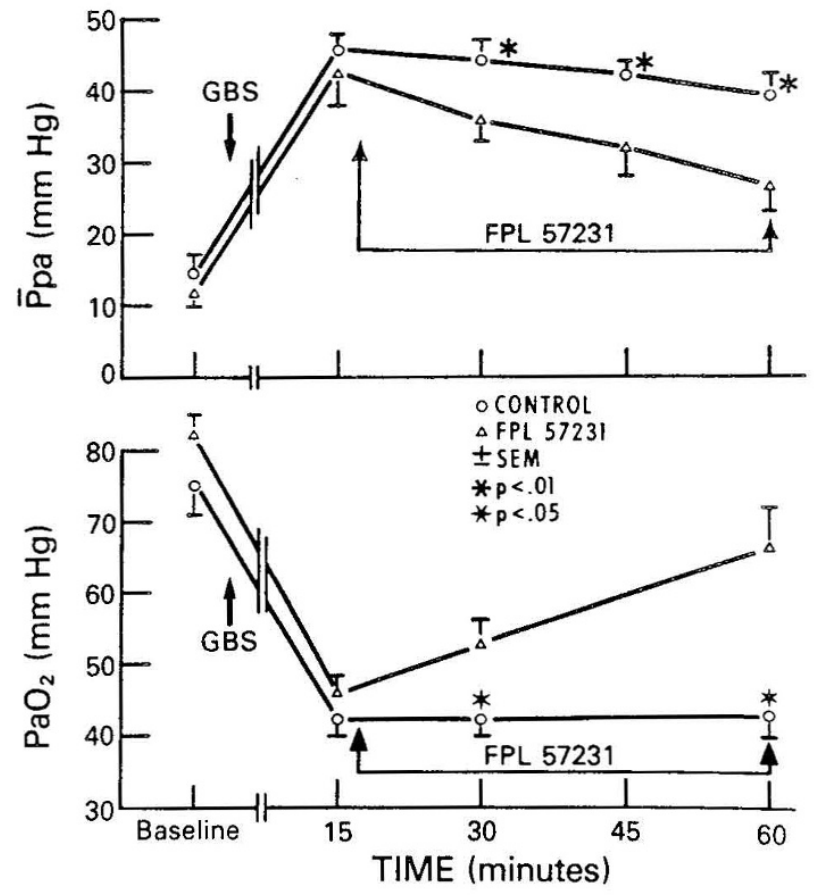

Fig. 1. Responses of mean pulmonary artery pressure and $\mathrm{PaO}_{2}$ to infusion of GBS. Effect of FPL 57231 on these measurements in the treatment group compared to the control group are shown. Duration of FPL 57231 infusion is noted by connected arrows. Significant differences between groups are indicated.

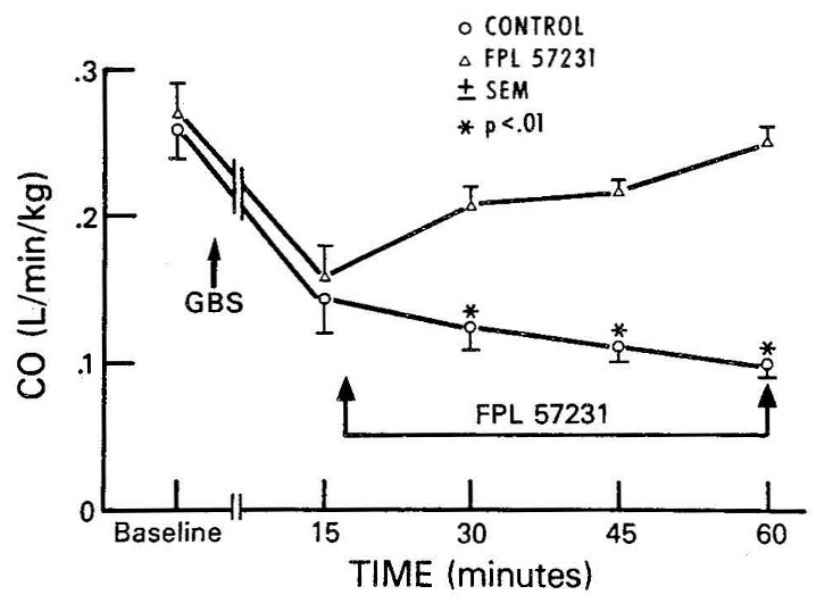

Fig. 2. Response of $\mathrm{CO}$ to the infusion of GBS. FPL 57231 infusion is noted by connected arrows.

$\mathrm{mm} \mathrm{Hg}(p<0.001)$. The Ppaw in control animals remained essentially unchanged while the Ppaw in the treatment group fell to values that were not significantly different from baseline. Right atrial pressure did not change significantly during the study period, nor were there statistical differences between groups.

Mean Psa and heart rate increased in both groups with GBS infusions, but were not statistically different over time from each other or from prebacterial infusion baseline at $60 \mathrm{~min}$.

Mean $\mathrm{TxB}_{2}$ values (Fig. 4) were significantly increased at 15 min after bacterial infusion began $(p<0.01)$ compared to baseline values in both groups. These values remained high during the study period, and groups were not significantly different.

Plasma concentrations of 6-keto $\mathrm{PGF}_{1 \alpha}$ were not different when baseline was compared to $15 \mathrm{~min}$. These values remained fairly stable throughout the study period. In addition the ratio of
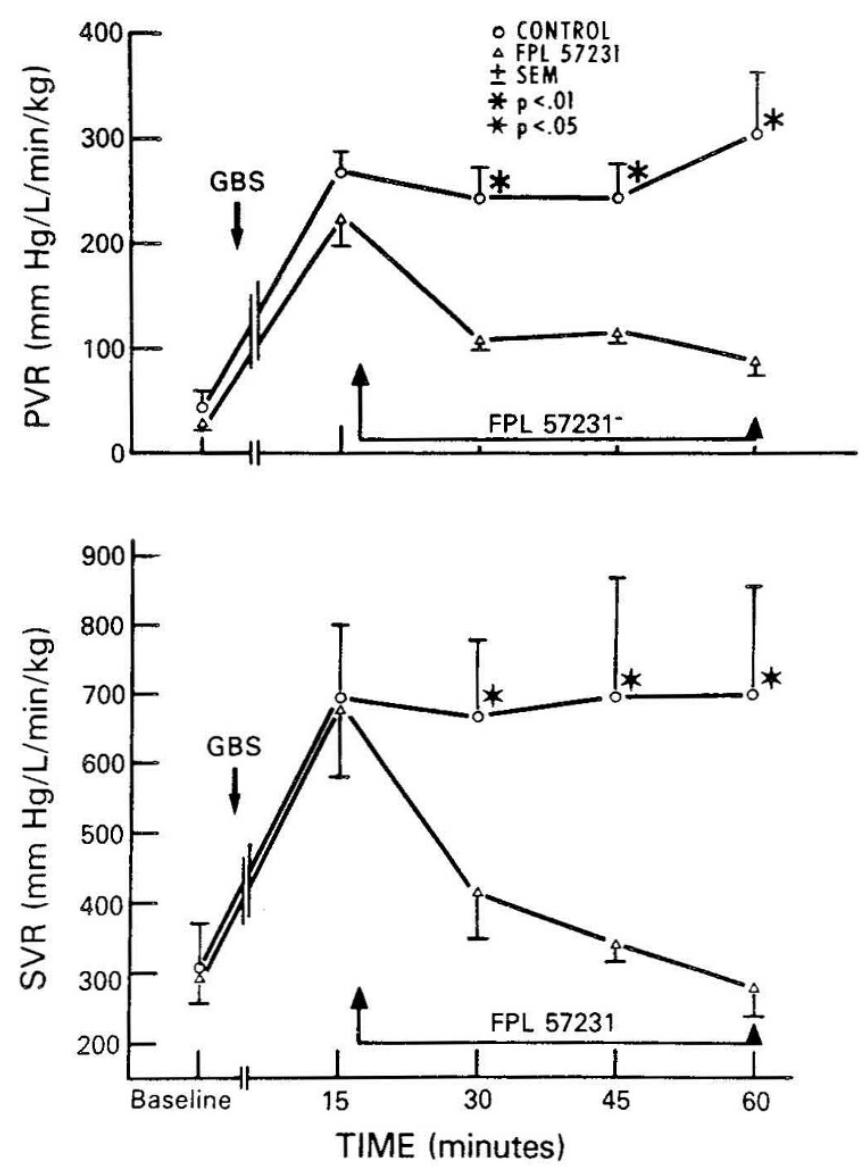

Fig. 3. Responses of pulmonary and systemic vascular resistances to infusion of GBS. FPL 57231 infusion in the treatment group is indicated by connected arrows.
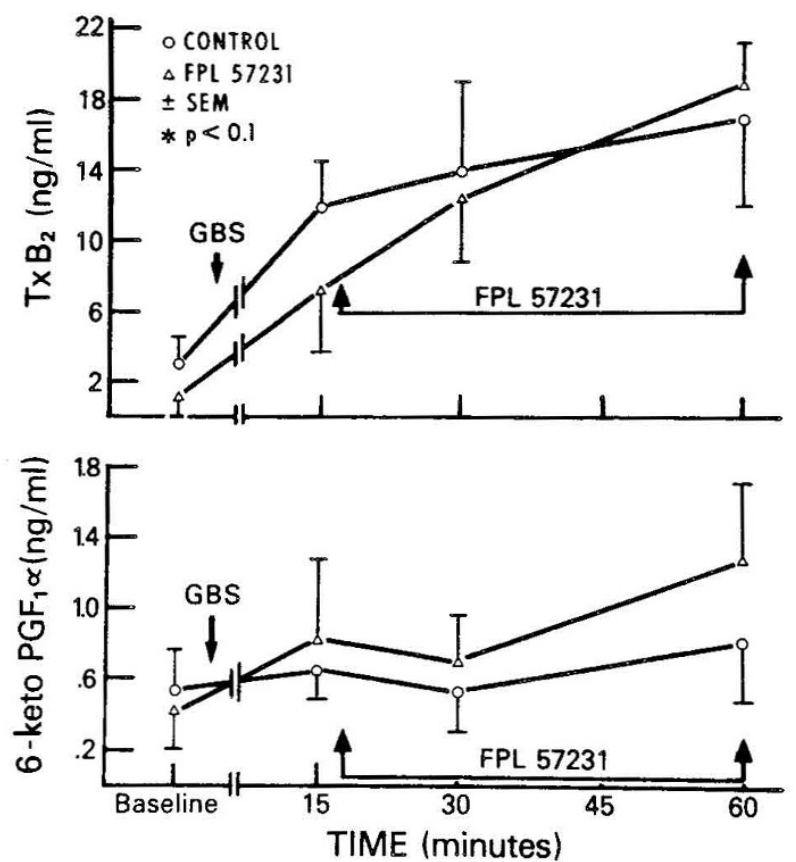

Fig. 4. Levels of $\mathrm{TxB}_{2}$ and 6-keto-PGF ${ }_{1 \alpha}$ in treatment and control groups are shown.

6-keto $\mathrm{PGF}_{1 \alpha}$ to $\mathrm{TxB}_{2}$ was not statistically different between groups.

Survival (mean \pm SD) was $100 \pm 32$ min in the control animals and $191 \pm 44 \mathrm{~min}$ in the treatment group $(p<0.01)$. Two of 
five controls and all five treatment animals were alive after $2 \mathrm{~h}$ of bacterial infusion.

\section{DISCUSSION}

The hemodynamic changes observed with an infusion of GBS or its extracellular toxin (i.e. an initial period of marked pulmonary hypertension followed by a later phase characterized by increased pulmonary vascular permeability and increased $\overline{\mathrm{P}} \mathrm{pa}$ ) are similar to those produced by an infusion of endotoxin (2, 4, 7). The initial phase of pulmonary hypertension is prevented by indomethacin given before and after the infusion of bacteria. The later phase is not affected by indomethacin, yet is prevented by steroids $(8,9)$. In addition, recent evidence suggests that the increase in pulmonary hypertension and PVR and the decrease in $\mathrm{CO}$ noted in this late phase of GBS sepsis are reversed by a leukotriene antagonist $(2,10)$.

One of the important effects of steroids when used in experimentally induced sepsis is the prevention of granulocyte depletion. This treatment has been shown to prevent the late occurring pulmonary vascular changes secondary to GBS toxin or endotoxemia $(8,9,11)$. A decrease in granulocyte numbers may occur within 15 to $30 \mathrm{~min}$ of initiation of experimental toxemia (1, 8, $9,11)$. This granulocytopenia, which appears to reach its nadir by $60 \mathrm{~min}(12)$, is associated with pathologic findings in the pulmonary vasculature characterized by capillaries which are filled with granulocytes undergoing degranulation and by disruption of the integrity of the endothelial basement and internal elastic membranes (12). This breakdown of granulocytes and their resulting products appear capable of injuring vascular endothelium $(13,14)$, a finding that may explain the late phase increased vascular permeability (12).

Furthermore, the observed increased level of 5-HETE a major product of leukocyte 5-lipoxygenation, may also reflect increased lipoxygenase activity and leukotriene production (15-18) in adult sheep treated with endotoxin, suggesting an early role for leukotrienes in the pathophysiology of sepsis $(12,18)$. This increase in 5 -HETE has been noted to occur within the 1 st $h$ after initiation of endotoxin infusion (18) and to reach its peak concentration following the initial period of severe pulmonary hypertension (19). The appearance of 5-HETE (18) in lung lymph during endotoxemia is suggestive evidence that lipoxygenase metabolites of arachidonic acid may be involved in the pulmonary vascular manifestations of sepsis. In addition, production of 5-HETE and other chemoattractants (e.g. leukotriene $\mathrm{B}_{4}$ ) by leukocytes trapped in the lung might perpetuate pulmonary leukostasis and thereby contribute to the pathogenesis of lung injury. The concept that lipoxygenase products may participate in ongoing leukostasis is also suggested by the neutropenia associated with intravenous administration of leukotriene $\mathrm{D}_{4}$ in primates $(20)$.

It seems reasonable to postulate from these data that the 5lipoxygenase products (5-HETE) which are produced and are released as granulocyte numbers decrease early on in endotoxemia, may also produce alterations in hemodynamics. Leukotriene $\mathrm{C}_{4}$ and $\mathrm{D}_{4}$ have been shown to increase $\overline{\mathrm{P}} \mathrm{pa}, \mathrm{PVR}$, and SVR, and decrease CO (21-23). In the present study we attempted to examine the hemodynamic effects of leukotrienes in the early phase (first $60 \mathrm{~min}$ ) of GBS sepsis using a competitive antagonist of leukotriene $\mathrm{C}_{4}$ and $\mathrm{D}_{4}, \mathrm{FPL} 57231(24,25)$. FPL 57231 appears to be a highly specific competitive receptor antagonist of leukotriene $\mathrm{D}_{4}$ in vivo $(24,25)$. The parent compound, FPL 55712, is one of a series of chromone-2-carboxylic acids, whereas FPL 57231 is a propionic acid analog of FPL 55712 (25). In addition, FPL 57231 appears to have a narrower range of antagonism than FPL 55712 (25).

FPL 57231 when given after the onset of sepsis caused a sudden improvement in $\mathrm{CO}$ and oxygenation, and a decline in PVR, SVR, and Ppaw to approximately baseline levels. In addition, it caused a progressive decline in Ppa. FPL 57231 also mitigated the fall in pH seen in control animals, and lengthened survival. These data suggest that leukotrienes, specifically $\mathrm{C}_{4}$ and $\mathrm{D}_{4}$, are released and are biologically active early on in the septic animal. Furthermore, these changes occurred without modification of $\mathrm{TxB}_{2}$, or 6 -keto $\mathrm{PGF}_{1 \alpha}$ levels.

The etiology of the myocardial depression in this model of sepsis is not clear $(2,26)$. Leukotrienes, specifically $D_{4}$, have been shown to depress $\mathrm{CO}$ and cause coronary artery vasoconstriction (27-29). The possibility that $\mathrm{TxA}_{2}$ effects cardiac function in GBS infection has been suggested $(2,26)$; however, in the present work a leukotriene antagonist resulted in a return of $\mathrm{CO}$ to baseline levels despite an elevated level of $\mathrm{TxB}_{2}$, suggesting that leukotrienes may also play a role in the myocardial dysfunction accompanying sepsis.

The apparent similarity in effect of $\mathrm{TxB}_{2}$ and leukotriene $\mathrm{C}_{4}$ and $\mathrm{D}_{4}$ on $\mathrm{CO}$ and to a lesser extent on pulmonary artery pressure is not easily explained. It is possible that their properties and/or sites of actions are similar. It has been suggested that in some species the action of leukotriene $\mathrm{C}_{4}$ and $\mathrm{D}_{4}$ may, in part, be mediated by $\mathrm{TxB}_{2}(30)$. This, however, appears to be related to species. In the pig (22) and in humans indomethacin does not block leukotriene action, suggesting that leukotriene $C_{4}$ and $D_{4}$ have relatively specific sites of action (31). Interestingly, it has been reported that a cyclooxygenase blocker may prevent enzymatic conversion of HPETE to HETE, both indicators of lipoxygenase activity, and hence interfere with lipoxygenation and possibly production of leukotrienes (32).

The potential for right to left shunting through fetal channels must be considered in a young animal model, however, this phenomenon appears to be minimal during room air breathing in the piglet by $48 \mathrm{~h}$ of age (33). In addition, work evaluating stressful experimental conditions such as sepsis $(2,34)$ and hypoxemia (35) have not shown evidence of shunting. Furthermore, during the increase in Ppa in the present study the peak pulmonary arterial systolic pressure was less than the systemic arterial diastolic pressure. Based on this pressure differential, it is unlikely that there was any significant ductal shunting or any flow right to left via the foramen ovali.

Caution must be exercised in attempting to extrapolate the results of this experiment to the clinical setting and to other experimental models. This model is rapidly lethal, unlike most cases of neonatal GBS disease. In addition, the absence of extrapulmonary right to left shunting also distinguishes this animal model from the human neonate. In contrast to other models, the one used also differs in that it uses a continuous infusion of organisms rather than a bolus of either toxin or bacteria and, in fact, this may result in an infusion of both toxin and live bacteria. The presence of an ongoing bacterial stimulus may account for the persistent elevation in plasma $\mathrm{TxB}_{2}$ concentration seen in control animals, in contrast to the peak and later decline in concentration of $\mathrm{TxB}_{2}$ reported by others $(36,37)$.

In conclusion, the findings of the present study suggest that FPL 57231, a leukotriene antagonist, significantly improves CO and oxygenation, decreases $\overline{\mathrm{Ppa}}$, and improves survival in a highly lethal model of group $\mathrm{B} \beta$-hemolytic streptococcal sepsis, suggesting that leukotriene $\mathrm{C}_{4}$ and $\mathrm{D}_{4}$ play an early role in hemodynamics. These effects appear to be independent and not mediated through $\mathrm{TxB}_{2}$ or 6-keto $\mathrm{PGF}_{1 \alpha}$ for the levels of the latter substances were unchanged during the study period.

Acknowledgments. The authors thanks to Ralph N. Cicalese for his indispensable technical assistance throughout this project, Glenda Brown for preparing this manuscript, Phil Sheard, M.Sc. and Fisons, pLc, Science and Technology Laboratories for their generous supply of FPL 57231, and Bill Feuer for his statistical guidance.

\section{REFERENCES}

1. Rojas J, Larson LE, Ogletree ML, Brigham KL, Stahlman MT 1983 Effects of cyclo-oxygenase inhibition on the response to group B streptococcal toxin in sheep. Pediatr Res 17:107-110 
2. Runkle B, Goldberg RN, Streitfeld MM, Clark MR, Buron E, Setzer ES, Bancalari E 1984 Cardiovascular changes in group B streptococcal sepsis in the piglet: responses to indomethacin and relationship to prostacyclin and thromboxane $\mathrm{A}_{2}$. Pediatr Res 18:874-878

3. Short BL, Miller MK. Fletcher JR 1982 Improved survival in the suckling rat model of group B streptococcal sepsis after treatment with nonsteroidal antiinflammatory drugs. Pediatrics 70:343-347

4. Ogletree ML, Brigham KL 1982 Effects of cyclooxygenase inhibitors on pulmonary vascular response to endotoxin in unanesthetized sheep. Prostaglandins Leukotrienes Med 8:489-502

5. Piper P, Marwa S, Tippins J, Williams T, Palman M, Peck M 1981 Pharmacological studies on pure SRS-A and synthetic leukotrienes $\mathrm{C}_{4}$ and $\mathrm{D}_{4} \mathrm{In}$ : Piper P (ed) SRS and Leukotrienes. John Wiley \& Sons, Ltd., New York, pp $81-99$

6. Winer BJ 1971 Statistical Principles in Experimental Design. McGraw Hill, New York

7. Rojas J, Green RS, Hellerqvist CG, Olegand R, Brigham KL, Stahlman MT 1981 Studies on group B beta-hemolytic streptococcus. II. Effects on pulmonary hemodynamics and vascular premeability in unanesthetized sheep. Pediatr Res 15:899-904

8. Brigham KL, Bowers RE, McKeen CR 1981 Methylprednisolone prevention of increased lung vascular permeability following endotoxemia in sheep. $J$ Clin Invest 67:1103-1110

9. Rojas J, Palme C, Ogletree ML, Hellerqvist CG, Brigham KL, Stahlman MT 1984 Effects of methylprednisolone on the response to group B streptococcal toxin in sheep. Pedaitr Res 18:1141-1144

10. Goldberg RN, Suguihara C, Streitfeld MM, Bancalari A, Clark MR, Bancalari E 1986 Effect of leukotriene antagonist FPL 57231 on the late hemodynamic manifestations of group B beta streptococcal sepsis. Pediatr Res 20:396A

11. Heflin AC, Brigham KL 1981 Prevention of granulocyte depletion and increased vascular permeability of sheep lung following endotoxemia. $\mathrm{J}$ Clin Invest 68:1253-1260

12. Rojas J, Larsson LE, Hellerqvist CG, Brigham KL, Gray ME, Stahlman MT 1983 Pulmonary hemodynamic changes associated with group B streptococcal toxemia in adult sheep and newborn lambs. Pediatr Res 17:1002-1008

13. Cochrance CG, Aikin BS 1966 Polymorphonuclear leukocytes in immunologic reactions. The destruction of vascular basement membrane in vivo and in vitro. J Exp Med 124:733-752

14. Goetzel EJ, Derian C, Valone FH 1980 The extracellular and intracellular role of hydroxy-eicosatetraenoic acid in the modulation of polymorphonuclear leukocyte and macrophage function. J Reticuloendothelial Soc 28:105s-111s

15. Borgeat P, Hamberg M, Samuelsson B 1976 Transformation of arachidonic acid and homo- $\gamma$-linolenic acid by rabbit polymorphonuclear leukocytes. $J$ Biol Chem 251:7816-7820

16. Hedqvist P, Dahlén SE, Gustafsson L, Hammarström SA, Samuelsson B 1980 Biological profiles of leukotrienes $C_{4}$ and $D_{4}$. Acta Physiol Scand 110:331333

17. Falkenhein SF, MacDonald H, Huber MM, Koch D, Parker CW 1980 Effect of the 5-hydroperoxide of eicosatetraenoic acid and inhibitor of the lipoxygenase pathway on the formation of slow-reading substance by rat basophilic cells; direct evidence that show reacting substance is a product of the lipoxygenase pathway. Immunology 125:163-168

18. Ogletree ML, Oates JA, Brigham KL, Hubbard WC 1982 Evidence for pulmonary release of 5-hydroxyeicosatetraenoic acid (5-HETE) during endotoxemia in unanesthetized sheep. Prostaglandins 23:459-468

19. Demling RH, Smith M, Gunther R, Flynn JT, Gee MH 1981 Pulmonary injury and prostaglandin production during endotoxemia in conscious sheep. Am J Physiol 240:H348-H353
20. Casey L, Clarke J, Fletcher J, Ramwell P 1982 Cardiovascular respiratory and hematologic effects of leukotriene $\mathrm{D}_{4}$ in primates. In: Samuelsson B, Paoletti $\mathrm{R}$ (eds) Advances in Prostaglandin Thromboxane and Leukotriene Research, Vol 9. Raven Press, New York, pp 201-209

21. Yokochi K, Olley PM, Sideris E, Hamilton F, Huktanen D, Coceani F 1982 Leukotriene $\mathrm{D}_{4}$ : a potent vasoconstrictor of the pulmonary and systemic circulations in the newborn lamb. In: Samuelsson B, Paoletti R (eds) Advances in Prostaglandin, Thromboxane and Leukotriene Research, Vol 9. Raven Press, New York, pp 211-214

22. Kadowitz PJ, Hyman AL 1984 Analysis of responses to leukotriene $\mathrm{D}_{4}$ in the pulmonary bed. Circ Res 55:707-717

23. Levi R, Burk JA, Corey EJ 1982 SRS-A, leukotrienes and immediate hypersensitivity reactions of the heart. In: Samuelsson B, Paoletti R (eds) Advances in Prostaglandins, Thromboxane and Leukotriene Research, Vol 9. Raven Press, New York, pp 215-221

24. Ahmed T, Yerger A, Warner A, Marchette B 1983 Pulmonary and systemic hemodynamic effects of leukotriene $\mathrm{D}_{4}$ : role of leukotriene receptor stimulation and cyclooxygenase metabolites. Fed Proc 42:A302

25. Sheard P, Holroyde MC Ghelani AM, Bantick JR, Lee TB 1982 Antagonist of SRS-A and leukotrienes. In: Samuelsson B, Paoletti R (eds) Advances in Prostaglandin, Thromboxane and Leukotriene Research, Vol 9. Raven Press, New York, pp 229-235

26. Peevy KJ, Chartrand SA, Wiseman HJ, Boerth RC, Olson RD 1985 Myocardial dysfunction in group B streptococcal shock. Pediatr Res 19:511-513

27. Iacopino VJ, Fitzpatrick TM, Ramwell PW, Rose JC, Kot PA 1983 Cardiovascular response to leukotriene $\mathrm{C}_{4}$ in the rat. $\mathrm{J}$ Pharmacol Exp Ther 227:224-247

28. Michelassi F, Landa L, Hill RD, Leweinstein E, Watkins WD, Petkau AS, Zapol WM 1982 Leukotriene $\mathrm{D}_{4}$ : a potent coronary artery vasoconstrictor associated with impaired ventricular contraction. Science 217:841-843

29. Pfeffer MA, Pfeffer JM, Lewis RA, Braunwald E, Corey EJ, Austen KF 1983 Systemic hemodynamic effects of leukotriene $\mathrm{C}_{4}$ and $\mathrm{D}_{4}$ in the rat. Am J Physiol 244:H628-H633

30. Engineer D, Morris M, Piper P, Sirois P 1978 The release of prostaglandins and thromboxanes from guinea pig lung by slow reacting substance of anaphylaxis and its inhibition. $\mathrm{Br} \mathrm{J}$ Pharmacol 64:211-218

31. Lelts LG, Cirino M, Lord A, Yusko F 1984 Actions of leukotrienes on blood vessel in vivo. Prostaglandins 28:602-604

32. Siegel MI, McConnel RT, Porter NA, Cuatrecasas P 1980 Arachidonate metabolism via lipoxygenase and $12 \mathrm{~L}$ hydroperoxy-5,8,10,14-ecosatetraenoic acid peroxidase sensitive to anti-inflammatory drugs. Proc Natl Acad Sci USA 77:308-312

33. Rowe RD, Sinclair JD, Kerr AR, Gage PW 1964 Ductal flow and mitral regurgitation during changes in oxygenation in newborn swine. $J$ App Physiol 19:1157-1162

34. Sorensen GK, Redding GJ, Troug WE 1985 Mechanisms of Pulmonary Gas exchange abnormalities during experimental groups B streptococcal infusion. Pediatr Res 19:922-926

35. Goldberg RN, Suguihara C, Ahmed T, de Cudemus BD, Barrios P, Setzer ES Bancalari E 1985 Influence of an antagonist of slow reacting substance of anaphylaxis on the cardiovascular manifestations of hypoxia in piglets. Pediatr Res 19:1201-1205

36. Fletcher JR, Ramwell PW, Harris RH 1981 Thromboxane, prostacyclin, and hemodynamic events in primate endotoxin shock. Adv Shock Res 5:143148

37. Frölich JC, Ogletree ML, Peskar BA, Brigham KL 1980 Pulmonary hypertension correlated to pulmonary thromboxane synthesis. Adv Prostaglandin Thromboxane Res 7:745-750 